\title{
Optimization of tube length by CFD analysis for heat transfer of sugar cane juice in a circular pipe using passive heat transfer technique of twisted tape
}

\author{
Abhijit A Patil ${ }^{\dagger}$, Uday C. Kapale ${ }^{\ddagger}$ and P. B. Gangawati† \\ †Department of Mechanical Engineering, Sanjay Ghodawat group of Institutions, Atigre, Kolhapur, Maharashtra, India \\ ‡Department of Mechanical Engineering, S. G. Balekundri Institute of Technology, Belgaum, Karnataka, India \\ †Department of Mechanical Engineering, VTU, Basveshwar Engineering college, Bagalkot, Karnataka, India \\ Accepted 02 Sept 2016, Available online 05 Sept 2016, Vol.6, No.5 (Oct 2016)
}

\begin{abstract}
Many papers in the last decade shows passive methods are more efficient for both laminar as well as turbulent type of flow. The present paper is a study of sugar cane juice evaporation process under laminar flow using twisted tape inserts. Various parameters like types of twists, tape materials, pipe geometry, type of fluid, twist ratio etc. were considered for the CFD analysis. These techniques give more effective results for the heat transfer process during evaporation.
\end{abstract}

Keywords: Brix, Heat transfer enhancement, twisted tape (TT), twist ratio, laminar flow.

\section{Introduction}

Heat transfer augmentation as enhancement is the process of improving the heat transfer rate of the system. It plays a very vital role in process industries to reduce the size, cost and the process time of the component. There are different techniques of augmentation briefly divided into three types as active methods, passive methods and compound methods, out of which the passive methods are used to increase heat transfer rate by using twisted tape, rough surfaces and additives in the base fluid etc. Heat transfer augmentation methods as discussed above are commonly used in the areas like process industries, refrigeration and air conditioning plants, heating and cooling in evaporators, thermal power plants, radiators in space vehicles, automobiles etc. Number of research papers shows that the passive techniques are most efficient where inserts are used in the flow passage to increase the heat transfer rate. The insert manufacturing process is also simple and as it doesn't requires external power. The disturbance made by the twists in the flow pattern results into production of some turbulism which highly impacts in the transfer of heat.

In the laminar flow, heat transfer mainly takes place by conduction and molecular diffusion as there is no cross mixing of the fluid. Natural convection current is also present but the thermal conductivities of the fluid

Abhijit A Patil, Uday C. Kapale and P. B. Gangawati are working as Assistant Professor, Dean \& Professor and Professor respectively are very low, with the exception of the liquid metals. Therefore the heat transfer rate in the conduction was generally low. In such situations passive methods of augmentation techniques by using twisted tapes are very efficient to increase heat transfer rate. Hence such implementation helps to reduce the size and cost of the equipment. The process time also becomes a part of interest with the application of twisted tapes.

On other hand, sugar factories play a very vital role the economic development of the nation. The sugar manufacturing from sugar cane juice consists of different processes like cane crushing, juice treatment, process of evaporation, crystallization pan treatment etc. Generally the process of evaporation is of five stages.

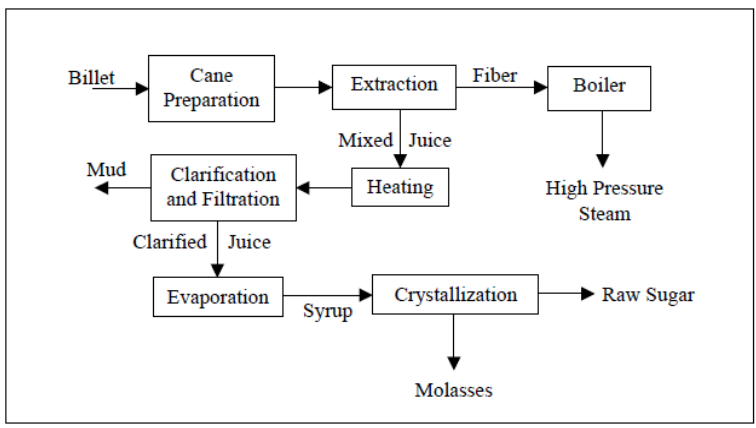

Fig. 1: crystal sugar making from sugar cane juice

Commonly used terminology and definitions for further discussions: 
Twist ratio- It is the ratio of inner diameter of the tube to the width of the TT insert.

Reynolds number- It is a dimensionless quantity which is used to decide the flow pattern.

Nusselt Number: It is the ratio of convective heat transfer to the conductive heat transfer across the boundary.

Hydraulic diameter- It is the ratio of cross-sectional area to the wetted perimeter of the cross section.

Brix: it is a measure of the concentration of the dissolved solid in solution.

Following research papers were considered for further analysis purpose.

(Hong \& Bergles,1976) shows that for laminar viscous fluid flowing in a tube with uniform heat flux boundary condition having co relations only restricted upto high Prandtl number (approx.730). The tape geometry plays a vital role in knowing circumferential temperature profile.

(Manglik \& Bergles, 1993) considers the effect of tube geometry and flow rate and its effect on heat transfer due to formation of large flow path and secondary fluid circulation. They develop the correlation between viscous, convective inertia and Nusselt number. The heat transfer correlation proposed by them is

$$
\mathrm{Nu}=4.162\left[6.413 \times 10^{-9}\left(S W \operatorname{Pr}^{0.391}\right)^{3.385}\right]^{0.2}\left(\frac{\mu}{\mu_{w}}\right)^{0.14}
$$

Where,

$\mathrm{SW}=$ swirl parameter and is given by $S W=R e / \sqrt{y}$ and for a correlation for the frictional factor,

Where

$$
\left(f R_{d}\right)_{S W}=15.767\left(\frac{\pi+2-2 t / d i}{\pi-4 t / d i}\right)^{2}\left(1+10^{-6} S W^{2.55}\right)^{1 / 6}
$$

$d i=$ Tube inner diameter and

$t=$ Thickness of the twisted tape.

(Saha et al.,2001) shows that the twisted tape with tight fit performs better than the TT inserted with loose fit. Also they focus on the non zero phase angle in between the segmented TT gives poor results.

(Saha \& Chakraborty,1997) studied the laminar flow heat transfer and pressure drop characteristics in a circular tube fitted with equispaced TT. They conclude that the there is a large pressure drop as compared to the reduction in the heat transfer.

(Patil,2000) observed that reduced width tape inserts gives $18 \%$ to $56 \%$ lower isothermal friction factor than the full width tape. For tape width of 19.7 and $11 \mathrm{~mm}$ Nusselt number decreases by $5 \%$ and $25 \%$.

(Krishna et al.,2009) studied heat transfer characteristics of a circular tube fitted with straight full twist insert. They observed that the heat transfer increase with Reynolds number and decreasing spacer distance (max. $50 \mathrm{~mm}$ ).
(Date,17) gave numerical prediction for the fully developed laminar flow heat transfer in a tube containing a twisted tape. He shows that the heat transfer increases about 15\% at Prandtl number of 150 and more.

(Saha et al.,2001) shows that the twisted tape with tight fit performs better than the TT inserted with loose fit. Also they focus on the non zero phase angle in between the segmented TT gives poor results.

(Ujhidy et al.,2003) studied the laminar flow with water coils and tubes containing TT and helical static elements. They results into a modified Dean number due to the curvature of the spherical line cut out by the helical element. The dean number is nothing but the measure of the magnitude of the secondary flow.

(Suresh kumar et al.,2013) observe the effect of TT insert in a large hydraulic diameter annulus. They proves that the thermohydraulic performance in a laminar flow with a TT performs better than the wire coil for the helix angle and thickness ratio.

(Wang \& Sunden, 2002)considers correlations for ethyl glycol and polybutene $(1000 \leq \operatorname{Pr} \leq 7000)$ and recommends TT are effective for small Prandtl number while wire coils are more effective for high Prandtl number (Pr $\geq 30)$

(Lokanath,1997) observed the effect of half length TT inserted with the flow of water through a horizontal tube. He concludes that the half length TT are more effective than the full length TT for a unit pumping power and a unit pressure drop.

It is proven that the tape inserts increases the heat transfer coefficient with the effect of pressure drop. The study is restricted only up to the laminar flow, as twisted tape inserts are more efficient to enhance heat transfer in such cases. The literature review includes different types of twisted tape inserts like full length twisted tape, full length TT using variable pitch, short length TT, fluids with different density, regularly spaced TT etc. The present CFD analysis is done to investigate the effect of equispaced TT in evaporator tube with laminar flow of sugarcane juice. The objective is to find out the effect on the parameters like heat transfer coefficient, overall heat transfer coefficient, Nusselt number etc.

\section{Specifications}

For the analysis purpose following data is selected.

1. Thickness of Tape : $3 \mathrm{~mm}$

2. Width of the tape: $42 \mathrm{~mm}$

3. Length of the tape: equals to length of the tube : $2000 \mathrm{~mm}, 2500 \mathrm{~mm}$

4. Tube dia. $\mathrm{Di}=42 \mathrm{~mm}$

5. Tube dia. $\mathrm{Do}=45 \mathrm{~mm}$

6. Density sugar juice: at $96^{\circ} \mathrm{C}=961.2 \mathrm{~kg} / \mathrm{m} 3$

7. specific heat sugar juice $(\mathrm{j} / \mathrm{kgk}): 4.21 \mathrm{KJ} / \mathrm{kgK}$

8. Thermal conductivity: Alluminium (food grade): $215 \mathrm{~W} / \mathrm{mK}$

9. stainless steel pipe(food grade): grade $316=16.3$ $\mathrm{w} / \mathrm{mK}$

10. dynamic viscosity $(\mathrm{kg} / \mathrm{ms}), 0.315 \mathrm{mPa} . \mathrm{s}(0.000315$ $\mathrm{kg} / \mathrm{ms}$ )

11. molecular weight $(\mathrm{kg} / \mathrm{kgmol})$ of Sugar Juice: 
12. Velocity of sugar juice entering the pipe: $0.0078 \mathrm{~m} / \mathrm{s}$

13. Mass of sugar juice entering the pipe: $5 \mathrm{Kg}$

14. Mass of sugar juice leaving the pipe: $3.015 \mathrm{Kg}$

15. Temperature of sugar juice entering the pipe: $98^{\circ} \mathrm{C}$

16. Temperature of sugar juice leaving the pipe: $94^{\circ} \mathrm{C}$

17. Temperature of steam entering the section: $112^{\circ} \mathrm{C}$

18. Temperature of steam entering the section: $103^{\circ} \mathrm{C}$

19. Mass of steam entering the section: $1 \mathrm{Kg}$

20. Mass of steam leaving the section: $0.923 \mathrm{Kg}$

\section{Geometrical modeling}

Plain tube can be developed by drawing two concentric circles of diameter $45 \mathrm{~mm}$ and $42 \mathrm{~mm}$ and extrude to get length $2000 \mathrm{~mm}$ and $2500 \mathrm{~mm}$. The models for this project work are developed by using CATIA V5 R18 software.

The complete plain tube pipe for the length $2000 \mathrm{~mm}$ model is shown in figure 2 below.

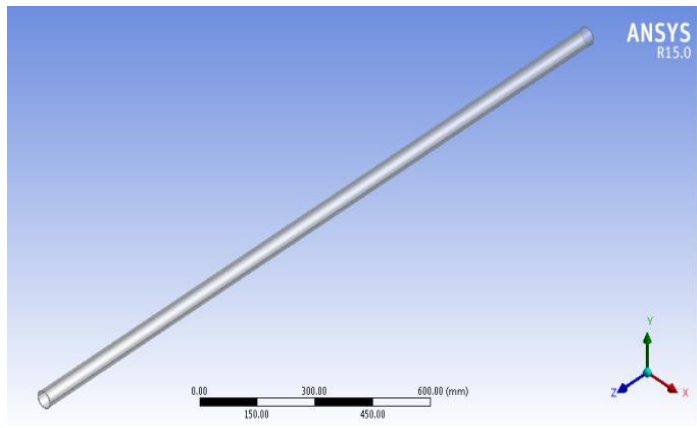

Fig. 2: plain tube of $2000 \mathrm{~mm}$

The tape insert with thickness $3 \mathrm{~mm}$ and width $42 \mathrm{~mm}$ for $2000 \mathrm{~mm}$ length is shown in figure 3 below.

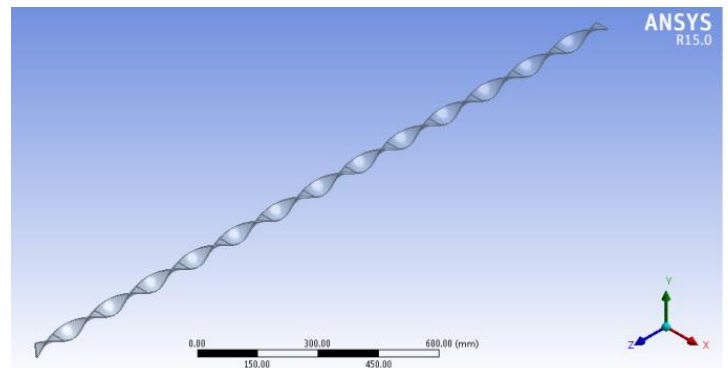

Fig.3: Tape insert for $2000 \mathrm{~mm}$

The complete plain tube with $2000 \mathrm{~mm}$ length with the tape insert is shown in figure 4 below.

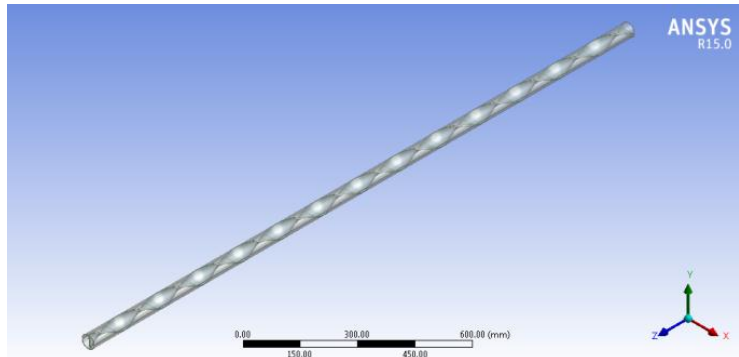

Fig. 4: Complete tube with tape insert

\section{Meshing and grid result analysis}

The meshing of the plain tube and the tape insert is done. The different parameters we need to define for generating the mesh. The following tube of plain mesh and with insert is as shown in fig. 5 and fig. 6 resp.

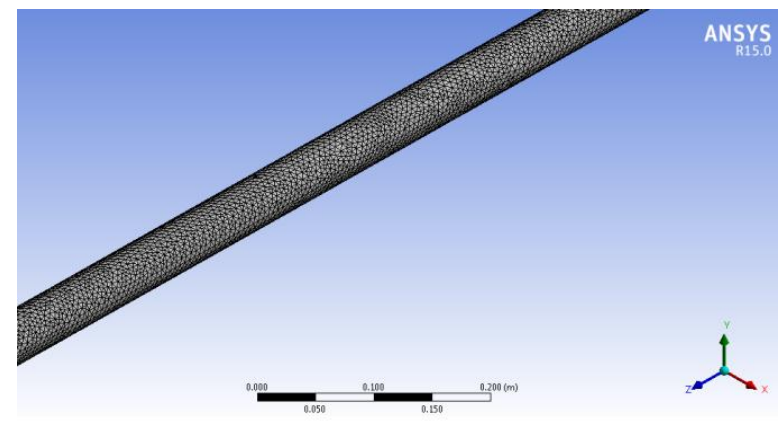

Fig. 5: Plain tube with mesh

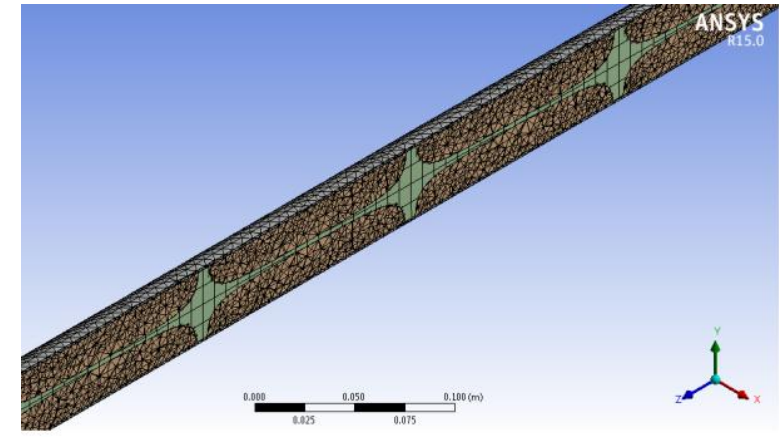

Fig. 6: Plain tube with TT mesh

Table 1: Details of meshing of plain tube

\begin{tabular}{|c|c|}
\hline $2000 \mathrm{~mm}$ Mesh Information & $\begin{array}{c}2500 \mathrm{~mm} \text { Mesh } \\
\text { Information }\end{array}$ \\
\hline No. of nodes $=60442$ & No. of nodes $=76114$ \\
\hline No. of elements $=218330$ & No. of elements $=279401$ \\
\hline Tetrahedra $=217354$ & Tetrahedra $=278453$ \\
\hline Hexahedra $=976$ & Hexahedra $=948$ \\
\hline
\end{tabular}

\section{Boundary physics of fluent}

The inlet and outlet boundary condition was taken as velocity-inlet, and pressure-outlet respectively. A constant heat flux condition was taken boundary condition for outer wall of pipe. The turbulence was captured by using k-epsilon model available in FLUENT.

\section{Results and discussions}

The results of CFD carried on a flowing fluid through a plain tube with equispaced insert and without insert for the length of $2000 \mathrm{~mm}$ and $2500 \mathrm{~mm}$ are shown below. For the analysis the tube thickness is neglected and the boundary conditions for this tube are considered as uniform heat flux. The heat flux on both the surfaces is assumed as same and the experiments are carried out. 
The insertion of twisted tape in pipe results in increase in turbulence which increases heat transfer coefficient value from $61.5 \mathrm{~W} / \mathrm{m} 2 \mathrm{~K}$ to $111.43 \mathrm{~W} / \mathrm{m} 2 \mathrm{~K}$ for $2000 \mathrm{~mm}$ pipe. The overall heat transfer coefficient and Nusselt Number also increases for $2000 \mathrm{~mm}$ pipes which are shown in table 4.

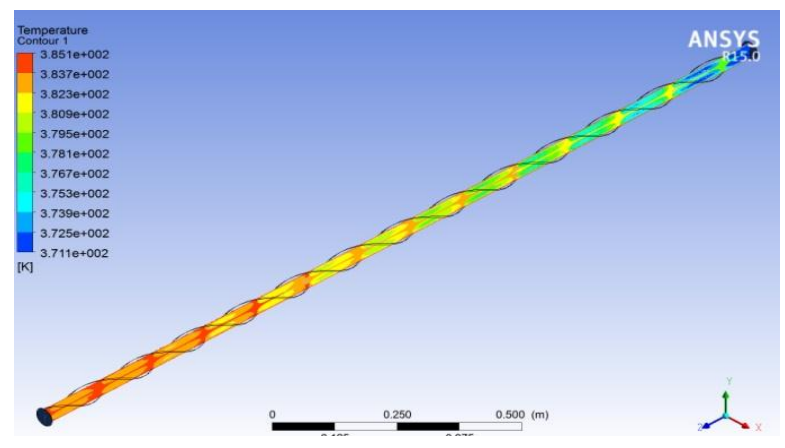

Fig. 7: 2000mm_with_TTI_Temperature

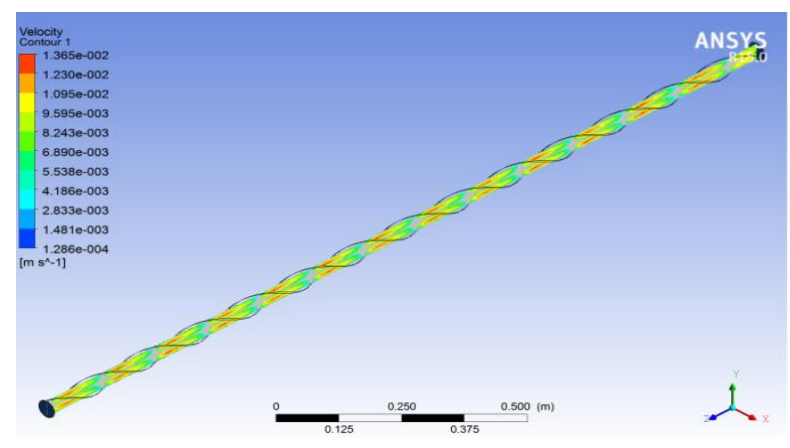

Fig. 8: 2000mm_with_TTI_Velocity

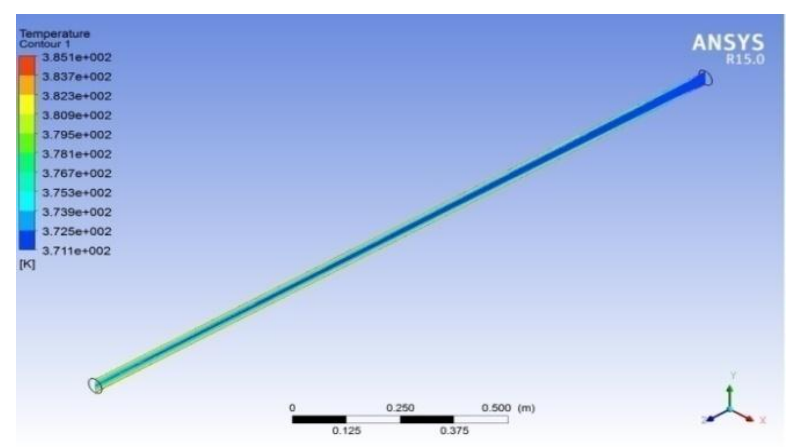

Fig 9: 2000mm_without_TTI_Temperature

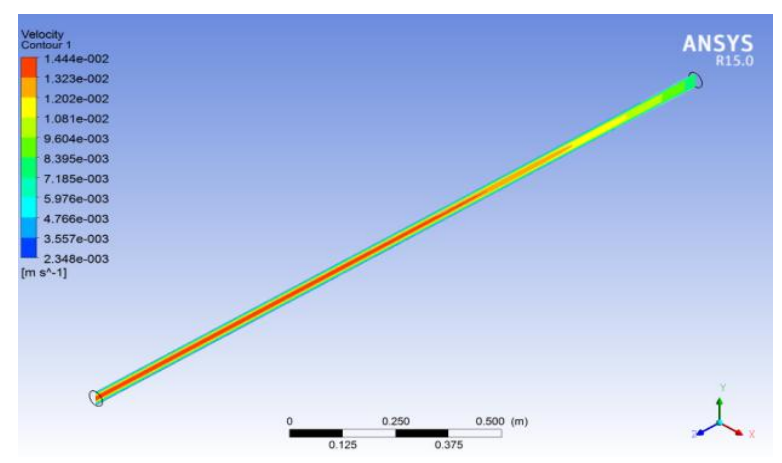

Fig. 10: 2000mm_without_TTI_Velocity

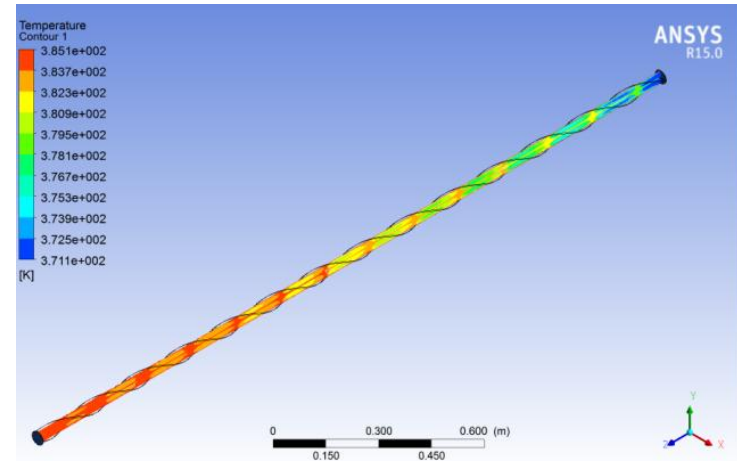

Fig. 11: 2500mm_with_TTI_Temperature

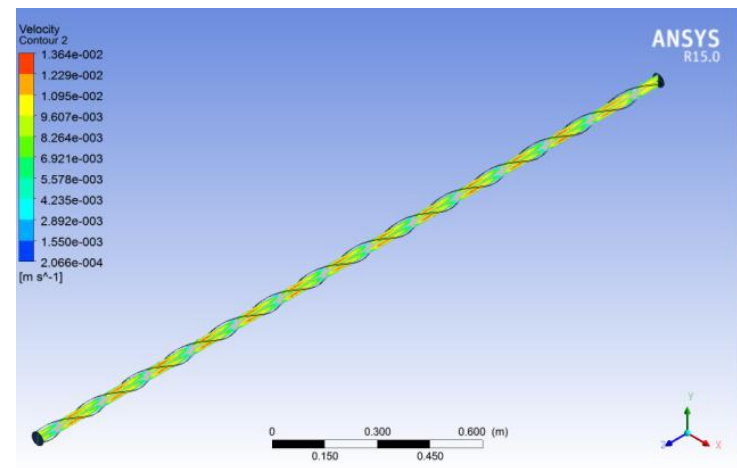

Fig. 11: 2500mm_with_TTI_velocity

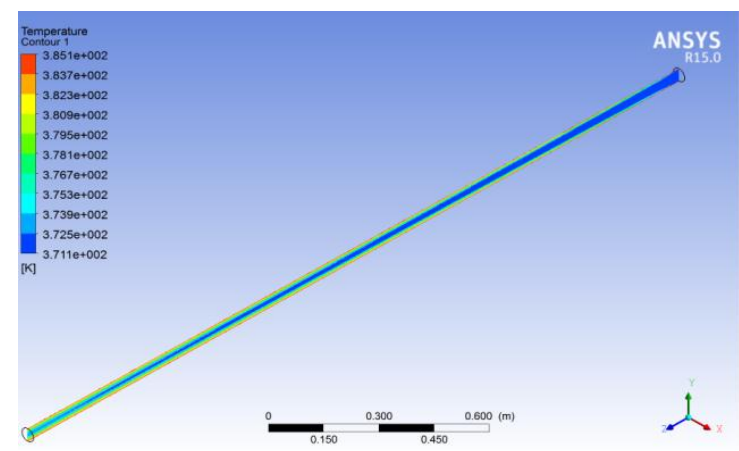

Fig. 12: 2500mm_without_TTI_Temperature

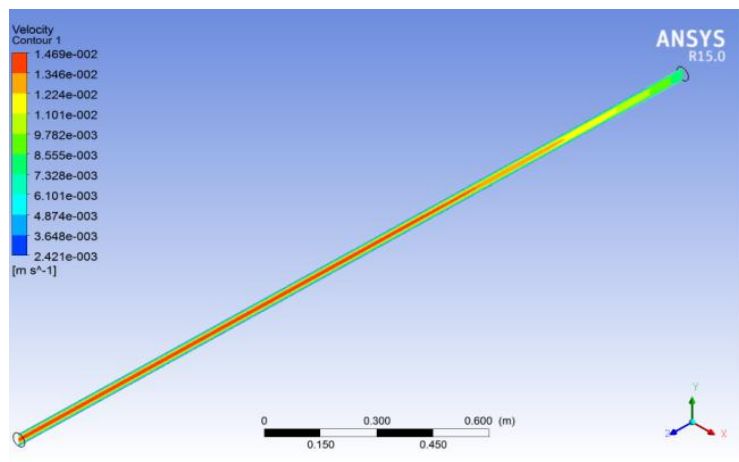

Fig. 13: 2500mm_without_TTI_velocity

But for $2500 \mathrm{~mm}$ pipe, the Nusselt number decreases with twisted tape. The heat transfer coefficient for the length of $2000 \mathrm{~mm}$ increases more as compared to the length of $2500 \mathrm{~mm}$. So it is recommended to use the pipe with the length of $2000 \mathrm{~mm}$ 
Table 2: Comparison of tube lengths with different parameters

\begin{tabular}{|c|c|c|c|c|}
\hline \multirow{3}{*}{ Parameters } & \multicolumn{2}{|c|}{$\begin{array}{c}\text { Without Twisted } \\
\text { Inserts }\end{array}$} & \multicolumn{2}{c|}{ With Twisted Inserts } \\
\cline { 2 - 5 } & $\mathrm{L}=2000$ & $\mathrm{~L}=2500$ & $\mathrm{~L}=2000$ & $\begin{array}{c}\mathrm{L}= \\
2500 \\
\mathrm{~mm}\end{array}$ \\
\hline $\mathrm{mm}$ & 61.5 & 51.17 & 111.43 & 107.61 \\
\hline $\mathrm{U}(\mathrm{W} / \mathrm{m} / \mathrm{m} 2 \mathrm{~K})$ & 137.89 & 147.04 & 151.35 & 8062.5 \\
\hline $\mathrm{Nu}$ & 87.87 & 85.28 & 185.73 & 179.31 \\
\hline $\begin{array}{c}\text { Avg. Temp. @ } \\
\text { outlet }(\mathrm{K})\end{array}$ & 377.94 & 379.67 & 383.78 & 384.19 \\
\hline
\end{tabular}

\section{Conclusion}

CFD simulation of heat transfer characteristics for a sugar cane juice in a circular tube using technique of Twisted Tape (TT) has been done. Various parameters like types of twists, tape materials, pipe geometry, type of fluid, twist ratio etc. were considered for the CFD analysis. The study was conducted under constant heat flux.

The heat transfer coefficient for the length of $2000 \mathrm{~mm}$ increases more as compared to the length of $2500 \mathrm{~mm}$. The overall heat transfer coefficient and Nusselt Number also increases for $2000 \mathrm{~mm}$ pipes. So it is recommended to use the pipe with the length of $2000 \mathrm{~mm}$

\section{References}

Hong, S. W. and Bergles, A. E. (1976), Augmentation of laminar flow heat transfer in tubes by means of twistedtape inserts. Trans. ASME J. Heat Transfer, 98, 251-256.

Manglik, R. M. and Bergles, A. E. (1993), Heat transfer and pressure drop correlations for twisted tape insert in isothermal tubes. Part 1: laminar flows. Trans. ASME, J. Heat Transfer,116, 881-889.
Saha, S. K., Dutta, A. and Dhal, S. K. (2001), Friction and heat transfer characteristics of laminar swirl flow through a circular tube fitted with regularly spaced twisted-tape elements. Int. J. Heat and Mass Transfer, 44, 4211-4223.

Saha, S. K. and Chakraborty, D. (1997), Heat transfer and pressure drop characteristics of laminar flow through a circular tube fitted with regularly spaced twisted tape elements with multiple twists. In Proceedings of 3rd ISHMT-ASME Heat and Mass Transfer Conference, India, pp. 313-318 (Tata McGraw-Hill, New Delhi).

Patil A.G. (2000), Laminar flow Heat Transfer and Pressure Drop Characteristics Power Low Fluid Inside Tubes with varying Width Twisted Tape Inserts, ASME 2000 vol. 122, pp149.

Krishna S.R. Pathipaka O., Sivashanmugam P. (2009), Heat transfer and Pressure Drop Studies in a Circular Tube Fitted with Straight Full Twist, Experimental Thermal and Fluid Science 33, pp.431-438.

DateA.W. , Prediction of Friction and Heat Transfer Characteristics of flow Tube Containing a Twisted tape, International Journal Heat Mass Transfer 17(8), 845-859.

Saha, S. K., Dutta, A. and Dhal, S. K. (2001), Friction and heat transfer characteristics of laminar swirl flow through a circular tube fitted with regularly spaced twisted-tape elements, Int. J. Heat and Mass Transfer, 44, 4211-4223.

Ujhidy, A., Nemeth, J. and Szepvolgyi, J. (2003), Fluid flow in tubes with helical elements, Chem. Engng and Processing,42, 1-7.

Suresh Kumar, P., Mahanta, P. and Dewan, A. (2003,), Study of laminar flow in a large diameter annulus with twisted tape inserts, In Proceedings of 2nd International Conference on Heat Transfer, Fluid Mechanics, and Thermodynamics, Victoria Falls, Zambia, paper KP3.

Wang, L. and Sunden, B. (2002), Performance comparison of some tube inserts, Int. Commun. Heat Transfer, 29, 45-56.

Lokanath, M. S. (1997), Performance evaluation of full length and half length twisted tape insertson laminar flow heat transfer in tubes, In Proceedings of 3rd ISHMT-ASME Heat and Mass Transfer Conference, India, pp. 319-324 (Tata McGraw-Hill, New Delhi). 